\title{
SUBSTRATOS PARA PRODUÇÃO DE MUDAS DE MAMONEIRA COMPOSTOS POR MISTURAS DE CINCO FONTES DE MATÉRIA ORGÂNICA
}

\author{
Substrates for castor seedlings production composed by blends of five organic materials
}

\author{
Rosiane de Lourdes Silva de Lima ${ }^{1}$, Liv Soares Severino ${ }^{2}$, Maria Isabel de Lima Silva ${ }^{3}$, \\ Jeane Ferreira Jerônimo ${ }^{4}$, Leandro Silva do Vale ${ }^{5}$, Napoleão Esberard de Macêdo Beltrão ${ }^{2}$
}

\begin{abstract}
RESUMO
O plantio de mamona (Ricinus communis L.) através de mudas pode ser uma alternativa para um melhor aproveitamento da curta estação chuvosa do semi-árido brasileiro, porém ainda não se dispõe de informações básicas para o emprego desta técnica. Na formulação de substratos para produção de mudas de mamona, as características físicas, principalmente a aeração, são fatores de grande importância. O presente estudo objetivou avaliar a composição de substratos utilizando misturas de solo, esterco bovino, casca de amendoim, mucilagem de sisal, bagaço de cana e cama de frango. Utilizou-se delineamento em blocos casualizados com 12 tratamentos e quatro repetições. Sementes da cultivar BRS Nordestina foram semeadas em sacos plásticos de $17 \mathrm{x} 28 \mathrm{~cm}$, contendo misturas dos materiais a serem testados. Valores de altura, área foliar, número de folhas e diâmetro caulinar foram registrados semanalmente entre 15 e 43 dias após a emergência. Na última coleta também se registraram a massa seca da parte aérea e das raízes. O substrato composto por solo + casca de amendoim + cama de frango + mucilagem de sisal propiciou o melhor crescimento das mudas. A cama de frango contribuiu para o enriquecimento químico do substrato, enquanto a casca de amendoim e a mucilagem de sisal contribuíram para adequar as características físicas de aeração e retenção de água.
\end{abstract}

Termos para indexação: Ricinus communis, esterco bovino, casca de amendoim, mucilagem de sisal, bagaço de cana, cama de frango.

\begin{abstract}
Planting castor (Ricinus communis L.) by seedlings can be an alternative for a better use of the short rainy season at brazilian semi-arid region, however there has been a lack of information necessary for this technique adoption. Physics characteristics, mainly aeration, are very important in a substrate for castor seedlings production. A trial was run in a randomized block design with 12 treatments and 4 replications in order to evaluate substrates for castor seedlings production. Treatments were blends of sand, bovine manure, peanut hulls, agave mucilage, sugarcane bagasse and poultry litter. Castor seeds cv. BRS 149 Nordestina were planted in plastic bags measuring 17 x $28 \mathrm{~cm}$ fulfilled with the substrates to be evaluated. Data on height, leaf area and stem diameter were weekly registered between 15 and 43 days after emergence. At the end of the trial shoot and root dry weight were measured. The substrate composed by sand+ peanut hulls + poultry litter + agave mucilage propitiated the best seedlings growth. Poultry litter contributed to chemical enrichment while peanut hulls and agave mucilage gave good aeration and water retention to the substrate.
\end{abstract}

Index terms: Ricinus communis, bovine manure, peanut hulls, agave mucilage, sugarcane bagasse, poultry litter.

(Recebido para publicação em 19 de abril de 2005 e aprovado em 6 de fevereiro de 2006)

\section{INTRODUÇÃO}

Entre as oleaginosas cultivadas no Brasil, a mamoneira (Ricinus communis L.) destaca-se pela rusticidade e boa adaptação a condições adversas de clima e solo, pelo rápido crescimento, elevada produção e considerável teor de óleo em suas sementes. De ocorrência natural na Etiópia e algumas regiões da Ásia (TÁVORA, 1982), esta espécie apresenta grande potencial produtivo, notadamente em áreas semi-áridas que dispõem de poucas alternativas agrícolas viáveis.

O início do desenvolvimento da parte aérea da mamoneira é muito lento no primeiro mês após o plantio. Sabendo-se que a estação chuvosa na região semi-árida é freqüentemente muito curta e irregular, a disponibilidade de mudas em adiantado estádio de desenvolvimento no início das chuvas pode ser uma grande vantagem para a cultura, permitindo-lhe estabelecer-se em campo em pouco tempo, levando vantagem sobre as plantas daninhas e aproveitando melhor o curto período em que há umidade disponível no solo.

Para a produção de mudas de mamoneira ainda não se dispõe de informações técnicas básicas como tamanho de recipientes, composição do substrato e tempo de permanência da muda em viveiro. Segundo Gomes \& Silva (2004), a escolha do substrato deve ser feita levando em consideração as características físicas e

${ }^{1}$ Engenheira Agrônoma, M.Sc.Doutoranda em Agronomia UNESP Jaboticabal - limarosiane@yahoo.com.br

2Pesquisador da Embrapa Algodão - Rua Oswaldo Cruz, 1143 - Campina Grande, PB - liv@cnpa.embrapa.br; nbeltrao@cnpa.embrapa.br

${ }^{3}$ Estudante de Biologia pela Universidade Estadual da Paraíba/UEPB - Estagiária da Embrapa Algodão.

${ }^{4}$ Bel. Estatística, Mestranda pela Universidade Estadual da Paraíba/UEPB;

${ }^{5}$ Estudante de Agronomia pela Universidade Federal Rural de Pernambuco/UFRPE - Estagiário da Embrapa Algodão. 
químicas exigidas pela espécie a ser plantada e aspectos econômicos, pois, além de propiciar adequado crescimento à planta, o material utilizado na composição do substrato deve ser abundante na região e ter baixo custo. Geralmente, os substratos são compostos por misturas de diferentes materiais, pois dificilmente um material puro conseguirá apresentar todas as características adequadas para compor um bom substrato (GOMES \& SILVA, 2004), podendo envolver até 4 ou mais materiais.

Do ponto de vista físico, o substrato deve permitir adequado crescimento das raízes, reter água, possibilitar aeração e agregação do sistema radicular, além de não favorecer o desenvolvimento de doenças e plantas daninhas. Quanto à composição química, deve fornecer todos os nutrientes necessários ao crescimento da planta em quantidade adequada e no momento que a planta apresenta a demanda. Para que o aporte de nutrientes seja adequado, é preciso haver boa capacidade de troca catiônica (CTC), pH próximo da neutralidade e baixa salinidade (condutividade elétrica).

Uma tendência geral para compor substratos para produção de mudas, tem sido a adição de fontes de matéria orgânica, a qual contribui não só para o fornecimento de nutrientes, mas também para as características físicas do meio de cultivo. Entre os materiais freqüentemente utilizados como substrato, citam-se: casca de arroz carbonizada (LUCAS et al., 2003), esterco bovino (CAVALCANTI et al., 2002), bagaço de cana (MELO et al., 2003), composto orgânico (TRINDADE et al., 2001), cama de frango e moinha de café (ANDRADE NETO et al., 1999), casca de Acácia-negra (SOUZA et al., 2003) e húmus de minhoca (LIMA et al., 2001).

A mamoneira é uma planta exigente em fertilidade (WEISS, 1983), mas a aeração das raízes é uma das mais importantes características para seu crescimento, como tem sido demonstrado por estudos que mostram seu sofrível crescimento em solos compactados (VALE et al., 2004) e sua extrema sensibilidade ao estresse por anoxia (encharcamento do solo) como verificado por Moraes \& Severino (2004) e Severino et al. (2004b).

O presente estudo teve o objetivo de avaliar substratos para produção de mudas de mamoneira compostos por diversas misturas de solo e materiais orgânicos (esterco bovino, casca de amendoim, mucilagem de sisal, bagaço de cana e cama de frango).

\section{MATERIAL E MÉTODOS}

O experimento foi conduzido a céu aberto, na Embrapa Algodão, Município de Campina Grande, PB, no período de maio a junho de 2004. Adotou-se o delineamento em blocos ao acaso, com 12 tratamentos e 4 repetições, sendo a parcela experimental representada por 2 sacos plásticos contendo uma planta em cada. Cada tratamento foi composto por uma mistura em partes iguais (em volume) de solo e fontes de matéria orgânica, ou seja, nas misturas triplas misturou-se $33,3 \%$ de cada material e na mistura quádrupla misturou-se $25 \%$ de cada material (Tabela 1). As fontes de matéria orgânica foram: esterco bovino, casca de amendoim, mucilagem de sisal, bagaço de cana e cama de frango, as quais foram submetidas a análise química para determinação do teor de nitrogênio, fósforo, potássio, cálcio, magnésio, e cinzas.

Os substratos foram acondicionados em sacos de polietileno medindo $17 \mathrm{~cm}$ de largura e $28 \mathrm{~cm}$ de comprimento. Foram utilizadas sementes de mamona da cultivar BRS Nordestina. A semeadura foi realizada diretamente nos recipientes, plantando-se três sementes por saco para posterior desbaste.

Registraram-se semanalmente os valores de crescimento em altura da planta, área foliar e diâmetro caulinar no período de 15 a 43 dias após a emergência (DAE). Na última avaliação, aos 43 DAE, tomou-se também o valor de massa seca da parte aérea e das raízes.

Calculou-se a área foliar pela fórmula $\mathrm{S}=0,2398 \times(\mathrm{L}$ $+\mathrm{P})^{1,9259}$ sugerida por Severino et al. (2004a), utilizando valores de largura da folha (L) e comprimento da nervura principal (P). Calculou-se o tamanho da folha pela divisão da área foliar pelo número de folhas. Os dados obtidos foram submetidos à análise de variância e as médias comparadas pelo Teste de Tukey a $1 \%$ de probabilidade.

\section{RESULTADOS E DISCUSSÃO}

A composição química das fontes de matéria orgânica está apresentada na Tabela 2. A cama de frango e a casca de amendoim apresentaram teores mais elevados de macronutrientes, sendo importantes no enriquecimento químico dos substratos. Para aumento da aeração do substrato (características físicas), foram importantes a adição de mucilagem de sisal, bagaço de cana e da casca de amendoim. O solo utilizado era composto por aproximadamente $95 \%$ de areia grossa + areia fina, com teores desprezíveis de nutrientes que pudessem contribuir para a composição química do substrato.

O resumo da análise de variância está apresentado na Tabela 3. Todas as características analisadas foram significativas a $1 \%$ pelo Teste F. Os Coeficientes de Variação foram considerados normais, na faixa de 10 a $25 \%$. 
TABELA 1 - Composição dos substratos testados para produção de mudas de mamona.

\begin{tabular}{ll}
\hline & \\
\hline Substrato 1 & Solo + esterco bovino + casca de amendoim \\
Substrato 2 & Solo + esterco bovino + mucilagem de sisal \\
Substrato 3 & Solo + esterco bovino + bagaço de cana \\
Substrato 4 & Solo + esterco bovino + cama de frango \\
Substrato 5 & Solo + casca de amendoim + mucilagem de sisal \\
Substrato 6 & Solo + casca de amendoim + bagaço de cana \\
Substrato 7 & Solo + casca de amendoim + cama de frango \\
Substrato 8 & Solo + mucilagem de sisal + bagaço de cana \\
Substrato 9 & Solo + mucilagem de sisal + cama de frango \\
Substrato 10 & Solo + bagaço de cana + cama de frango \\
Substrato 11 & Solo + casca de amendoim + cama de frango + mucilagem de sisal \\
Substrato 12 & Solo \\
\hline
\end{tabular}

TABELA 2 - Composição química das fontes de matéria orgânica utilizadas na formulação dos substratos avaliados. Campina Grande, PB, 2004.

\begin{tabular}{lcccccc}
\hline \multicolumn{1}{c}{ Material } & N & P & K & Ca & Mg & Cinzas \\
\hline Bagaço de cana & 0,24 & 0,20 & 0,11 & 0,39 & 0,45 & 18,5 \\
Casca de amendoim & 1,54 & 0,36 & 0,79 & 0,46 & 0,21 & 3,5 \\
Esterco bovino & 0,78 & 0,87 & 0,33 & 0,31 & 0,18 & - \\
Mucilagem de sisal & 0,12 & 0,01 & 0,10 & 0,40 & 0,24 & - \\
Cama de frango & 2,95 & 3,97 & 1,10 & 4,71 & 6,93 & - \\
\hline
\end{tabular}

Os valores de todas as características estudadas estão apresentados na Tabela 4. O substrato composto apenas por solo não possibilitou o crescimento das plantas devido à falta de nutrientes. As reservas contidas na semente da mamona foram suficientes somente para o crescimento inicial das plantas, as quais apresentaram folhas pequenas e pouco numerosas, caules finos e pequena quantidade de matéria seca da parte aérea ou radicular.

O substrato composto por solo + casca de amendoim + cama de frango + mucilagem de sisal propiciou o melhor crescimento em quase todas as características analisadas e o substrato contendo as mesma fontes de materia orgânica exceto a mucilagem de sisal, foi considerado o segundo melhor substrato. Possivelmente, este substrato mostrou-se adequado em função da boa aeração na casca de amendoim e mucilagem de sisal, complementada pela boa disponibilidade de nutrientes propiciada pela cama de frango (Tabela 1). Os macroporos formados pela casca de amendoim pode ser vistos na Figura 1.

Chama a atenção o fato da casca de amendoim também fazer parte da composição do substrato que propiciou o pior crescimento das mudas, por ter sido associado ao bagaço de cana que é um material quimicamente inativo (Tabela 1). Embora a casca de amendoim possua altos teores de nutrientes (Tabela 1), o material não foi triturado e o tamanho das partículas foi impeditivo para que houvesse decomposição e mineralização dos nutrientes no curto período de produção de mudas (Figura 1). Dessa forma, a casca de amendoim

Ciênc. agrotec., Lavras, v. 30, n. 3, p. 474-479, maio/jun., 2006 
contribuiu para melhor aeração do substrato, mas teve pouca contribuição como fornecedor de nutrientes.

Percebeu-se que de forma geral os substratos contendo bagaço de cana não foram adequados para o crescimento da mamoneira, possivelmente porque a alta relação $\mathrm{C} / \mathrm{N}$ induziu a carência de Nitrogênio no substrato, tendência confirmada por Gomes \& Silva (2004). Os resultados apresentados por Lima et al. (2004) confirmam que a mucilagem de sisal e o bagaço de cana misturados apenas com solo compuseram um substrato inadequado para produção de mudas de mamona.

A cama de frango mostrou-se uma fonte orgânica quimicamente ativa, compondo um bom substrato sempre que associada com um material que propicie boas características físicas como a casca de amendoim ou a mucilagem de sisal. Lima et al. (2004) observaram que a cama de frango misturada apenas ao solo não propiciou adequado crescimento de mudas de mamoneira, confirmando ser este material adequado quimicamente, mas deficiente do ponto de vista físico.

Na Figura 2 está apresentada a evolução da altura, área foliar, tamanho da folha e diâmetro caulinar dos dois melhores e dos dois piores substratos. Entre os piores não se incluiu o Substrato 12 (solo puro), pois este foi considerado um tratamento controle sem interesse prático. Aos 43 DAE, quando o experimento foi finalizado, as mudas ainda estavam em pleno crescimento, evidenciando que ainda não havia limitação nutricional, hídrica ou de espaço no recipiente para a sustentação da planta.

TABELA 3 - Resumo da análise de variância da altura, diâmetro caulinar, área foliar, número de folhas, tamanho da folha, massa seca da parte aérea (MSPA) e massa seca das raízes (MSR) em mudas de mamonas cultivadas em substratos compostos por diferentes misturas de fontes de matéria orgânica. Campina Grande, PB, 2004.

\begin{tabular}{lcccccccc}
\hline F.V. & G.L. & Altura & $\begin{array}{c}\text { Diâmetro } \\
\text { caulinar }\end{array}$ & $\begin{array}{c}\text { Área foliar } \\
\text { folhas }\end{array}$ & $\begin{array}{c}\mathbf{N}^{\mathbf{2}} \\
\text { da folha }\end{array}$ & MSPA & MSR \\
\hline Tratam. & 11 & $128,5 * *$ & $19,1 * *$ & $940.692 * *$ & $1,52 * *$ & $42097,7 * *$ & $61,6 * *$ & $14,2^{* * *}$ \\
Bloco & 3 & 2,1 & 2,2 & 52.504, & 0,08 & $2.788,9$ & 1,0 & 0,7 \\
Erro & 33 & 12,1 & 0,79 & 23.506, & 0,30 & $1.334,3$ & 1,5 & 0,66 \\
\hline CV $(\%)$ & & 14,2 & 11,3 & 21,4 & 13,7 & 21,2 & 20,8 & 25,3 \\
\hline
\end{tabular}

Valores seguidos ** são significativos pelo Teste $\mathrm{F}$ a $1 \%$.

TABELA 4 - Valores de altura, área foliar, diâmetro caulinar, número de folhas, tamanho da folha, massa seca da parte aérea (MSPA) e massa seca de raízes (MSR) de mudas de mamoneira cultivadas em substratos compostos por misturas de solo (A), esterco bovino (EB), casca de amendoim (CA), mucilagem de sisal (MS), bagaço de cana (BC) e cama de frango (CF). Campina Grande, PB, 2004.

\begin{tabular}{llllllll}
\hline \multicolumn{1}{c}{ Substrato } & Altura $(\mathbf{c m})$ & $\begin{array}{c}\text { Área foliar } \\
\left(\mathbf{c m}^{\mathbf{2}}\right)\end{array}$ & $\begin{array}{c}\text { Diâmetro } \\
\text { caulinar }(\mathbf{m m})\end{array}$ & $\mathbf{N}^{\mathbf{0}}$ folhas & $\begin{array}{c}\text { Tamanho da } \\
\text { folha }\left(\mathbf{c m}^{\mathbf{2}}\right)\end{array}$ & MSPA (g) & MSR (g) \\
\hline A+EB+CA & $24,65 \mathrm{abcd}$ & $611,95 \mathrm{~cd}$ & $9,63 \mathrm{abc}$ & $3,75 \mathrm{abc}$ & $163,19 \mathrm{de}$ & $7,14 \mathrm{bc}$ & $3,73 \mathrm{bc}$ \\
$\mathrm{A}+\mathrm{EB}+\mathrm{MS}$ & $32,75 \mathrm{a}$ & $873,03 \mathrm{c}$ & $9,74 \mathrm{ab}$ & $4,25 \mathrm{abc}$ & $205,42 \mathrm{bcd}$ & $8,25 \mathrm{~b}$ & $5,36 \mathrm{ab}$ \\
$\mathrm{A}+\mathrm{EB}+\mathrm{BC}$ & $19,63 \mathrm{cde}$ & $197,50 \mathrm{e}$ & $5,13 \mathrm{e}$ & $5,00 \mathrm{a}$ & $39,50 \mathrm{f}$ & $1,50 \mathrm{e}$ & $1,54 \mathrm{~d}$ \\
A+EB+CF & $21,00 \mathrm{bcde}$ & $650,28 \mathrm{~cd}$ & $7,65 \mathrm{bcd}$ & $3,50 \mathrm{bc}$ & $185,79 \mathrm{~cd}$ & $3,38 \mathrm{de}$ & $1,33 \mathrm{~d}$ \\
$\mathrm{~A}+\mathrm{CA}+\mathrm{MS}$ & $32,68 \mathrm{a}$ & $906,90 \mathrm{bc}$ & $9,30 \mathrm{abc}$ & $3,75 \mathrm{abc}$ & $241,84 \mathrm{bcd}$ & $9,37 \mathrm{~b}$ & $5,50 \mathrm{ab}$ \\
$\mathrm{A}+\mathrm{CA}+\mathrm{BC}$ & $19,18 \mathrm{de}$ & $170,65 \mathrm{e}$ & $5,09 \mathrm{e}$ & $3,50 \mathrm{bc}$ & $48,76 \mathrm{f}$ & $1,28 \mathrm{e}$ & $0,85 \mathrm{~d}$ \\
$\mathrm{~A}+\mathrm{CA}+\mathrm{CF}$ & $28,00 \mathrm{abc}$ & $1285,50 \mathrm{a}$ & $9,93 \mathrm{a}$ & $4,75 \mathrm{ab}$ & $270,63 \mathrm{abc}$ & $9,27 \mathrm{~b}$ & $4,61 \mathrm{ab}$ \\
A+MS+BC & $22,25 \mathrm{bcde}$ & $283,48 \mathrm{de}$ & $5,61 \mathrm{de}$ & $3,75 \mathrm{abc}$ & $75,59 \mathrm{ef}$ & $2,16 \mathrm{de}$ & $1,82 \mathrm{~cd}$ \\
A+MS+CF & $27,18 \mathrm{abcd}$ & $1275,55 \mathrm{ab}$ & $9,53 \mathrm{abc}$ & $4,50 \mathrm{ab}$ & $283,46 \mathrm{ab}$ & $9,31 \mathrm{~b}$ & $4,54 \mathrm{ab}$ \\
A+BC+CF & $24,00 \mathrm{bcd}$ & $612,30 \mathrm{~cd}$ & $7,45 \mathrm{~cd}$ & $3,75 \mathrm{abc}$ & $163,28 \mathrm{de}$ & $4,74 \mathrm{~cd}$ & $2,21 \mathrm{~cd}$ \\
A+CA+CF+MS & $28,88 \mathrm{ab}$ & $1599,90 \mathrm{a}$ & $10,79 \mathrm{a}$ & $4,75 \mathrm{ab}$ & $336,82 \mathrm{a}$ & $12,45 \mathrm{a}$ & $5,79 \mathrm{a}$ \\
Solo & $14,00 \mathrm{e}$ & $143,38 \mathrm{e}$ & $5,07 \mathrm{e}$ & $3,00 \mathrm{c}$ & $47,79 \mathrm{f}$ & 1,19 & $1,25 \mathrm{~d}$ \\
\hline$\Delta$ (Teste Tukey) & 8,58 & 377,93 & 2,19 & 1,36 & 90,04 & 2,99 & 2,00 \\
\hline
\end{tabular}

* valores seguidos da mesma letra (na coluna) não diferem entre si pelo teste de Tukey (p>0,05). 


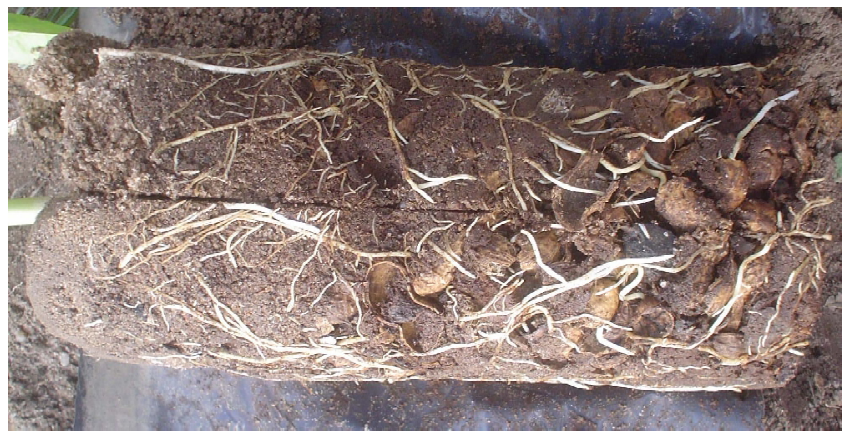

FIGURA 1 - Substrato contendo casca de amendoim no qual se observa a presença de macroporos e bom desenvolvimento das raízes das mudas de mamoneira. Campina Grande, PB, 2004.
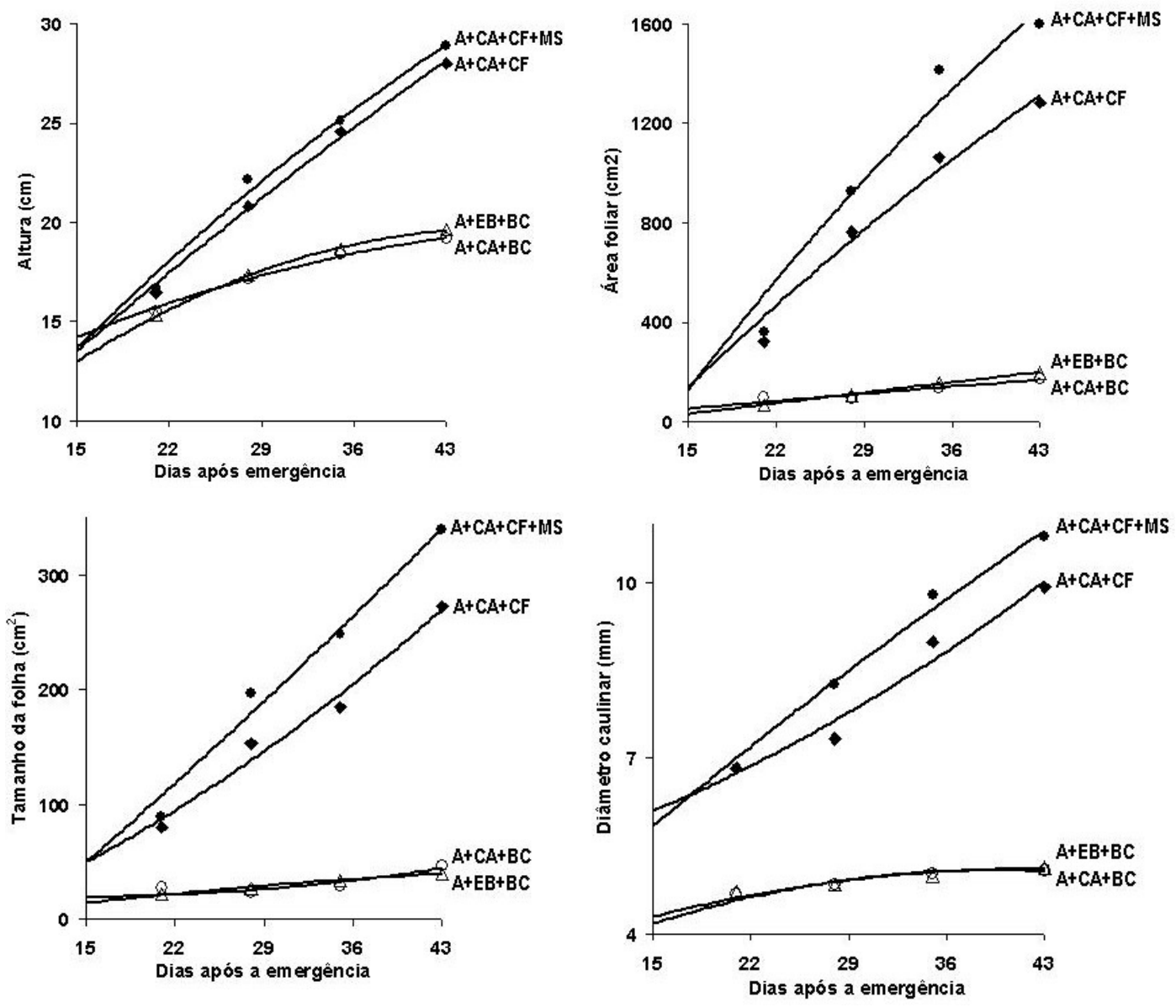

FIGURA 2 - Evolução da altura, área foliar, tamanho da folha e diâmetro caulinar de mudas de mamoneira cultivadas em substratos compostos por misturas de solo (A), casca de amendoim (CA), cama de frango (CF), esterco bovino (EB) e bagaço de cana (BC). Campina Grande, PB, 2004.

Ciênc. agrotec., Lavras, v. 30, n. 3, p. 474-479, maio/jun., 2006 


\section{CONCLUSÕES}

O substrato composto por mistura de solo + casca de amendoim + cama de frango + mucilagem de sisal possibilitou o melhor crescimento das plantas de mamoneira, cultivar Nordestina, plantadas em saquinhos.

Os substratos contendo bagaço de cana, de forma geral, se mostraram inadequados para a produção de mudas de mamoneira.

A cama de frango mostrou-se uma boa fonte de nutrientes para a composição do substrato, necessitando ser combinada com um material que propicie condições físicas adequadas.

A casca de amendoim e a mucilagem de sisal contribuíram para a melhoria das características físicas do substrato para produção de mudas de mamoneira.

\section{AGRADECIMENTOS}

Os autores agradecem o apoio financeiro recebido da Petrobras para realização deste estudo.

\section{REFERÊNCIAS BIBLIOGRÁFICAS}

ANDRADE NETO, A. de; MENDES, A. N. G.; GUIMARÃES, P. T. G. Avaliação de substratos alternativos e tipos de adubação para a produção de mudas de cafeeiro (Coffea arábica L.) em tubetes. Ciência e Agrotecnologia, Lavras, v. 23, n. 2, p. 270-280, 1999.

CAVALCANTI, N. B.; RESENDE, G. M.; BRITO, L. T. L. Emergência e crescimento do imbuzeiro (Spondias tuberosa) em diferentes substratos. Revista Ceres, Viçosa, v. 49, n. 282, p. 97-108, 2002.

GOMES, J. M.; SILVA, A. R. Os substratos e sua influência na qualidade de mudas. In: BARBOSA, J. G.; MARTINEZ, H. E. P.; PEDROSA, M. W.; SEDIYAMA, M. A. N. Nutrição e adubação de plantas cultivadas em substratos. Viçosa: UFV, 2004, p. 190-225.

LIMA, R. L. S.; FERNANDEZ, V. L. B.; OLIVEIRA, V. H.; HERNANDEZ, F. F. F. Crescimento de mudas de cajueiro anão precoce CCP-76 submetidas a adubação orgânica e mineral. Revista Brasileira de Fruticultura, Jaboticabal, v. 23, n. 2, 2001.

LIMA, R. L. S.; SEVERINO, L. S.; SILVA, M. I. L.; JERÔNIMO, J. F.; VALE, L. S.; PAIXÃO, F. J. R.; BELTRÃO, N. E. M. Substratos para produção de mudas de mamona 3: mucilagem de sisal associada a quatro fontes de matéria orgânica. In: CONGRESSO BRASILEIRO DE MAMONA, 1., 2004, Campina Grande. Anais... Campina Grande: Embrapa Algodão, 2004. CD-ROM.
LUCAS, M. A. K.; SAMPAIO, N. V.; KOHN, E. T.; SOARES, P. F.; SAMPAIO, T. G. Avaliação de diferentes composições de substratos para a aclimatação de mudas de morangueiro (Fragaria $x$ ananassa Duch.). Revista Ciência Rural, Santa Maria, v. 8, n. 1, p. 16-23, 2003.

MELO, A. S.; BRITO, M. E. B.; GOIS, M. P. P.; BARRETO, M. C. V.; VIEGAS, P. R. A.; HOLANDA, F. S. R. Efeito de substratos orgânicos organo-minerais na formação de mudas de maracujazeiro (Passiflora edulis). Revista Científica Rural, [S.1.], v. 8, n. 2, p. 116-121, 2003.

MORAES, C. R. A.; SEVERINO, L. S. Influência da saturação hídrica do solo sobre o desenvolvimento da mamoneira. In: CONGRESSO BRASILEIRO DE MAMONA, 1., 2004, Campina Grande. Anais... Campina Grande: Embrapa Algodão, 2004. CD-ROM.

SEVERINO, L. S.; CARDOSO, G. D.; VALE, L. S.; SANTOS, J. W. Método para determinação da área foliar da mamoneira. Revista Brasileira de Oleaginosas e Fibrosas, Campina Grande, v. 8, n. 1, p. 753-762, 2004a.

SEVERINO, L. S.; LIMA, C. L. D.; BELTRÃO, N. E. M.; CARDOSO, G. D.; FARIAS, V. A. Mamoneira submetida a encharcamento do solo. In: CONGRESSO BRASILEIRO DE MAMONA, 1., 2004, Campina Grande. Anais... Campina Grande: Embrapa Algodão, 2004b. CD-ROM.

SOUZA, P. V.; CARNIEL, E.; SCHMITZ, J. A. K.; SILVEIRA, S. V. da. Substratos e fungos micorrízicos arbusculares no desenvolvimento vegetativo de Citrange Troyer. Agropecuária Catarinense, Florianópolis, v. 16, n. 3, p. 84-88, 2003.

TÁVORA, F. J. A. F. A. A cultura da mamona. Fortaleza: Epace, 1982. 111 p.

TRINDADE, A. V.; MUCHOVEJ, R. M. C.; NEVES, J. C. L.; BARROS, N. F. Crescimento e nutrição de mudas de Eucaliptus grandis em resposta a composto orgânico ou adubação mineral. Revista Ceres, Viçosa, v. 276, n. 48, p. 181-194, 2001.

VALE, L. S.; COSTA, J. V. T.; LIMA, R. L. S.; SILVA, M. I. L.; SEVERINO, L. S.; BELTRÃO, N. E. M.; CARDOSO, G. D. Crescimento da mamoneira em solo compactado. In: CONGRESSO BRASILEIRO DE MAMONA, 1., 2004, Campina Grande. Anais... Campina Grande: Embrapa Algodão, 2004. CD-ROM.

WEISS, E. A. Castor. In: . Oil seed crops. London: Longman, 1983, p. 31-99. 